Tropical Journal of Pharmaceutical Research January 2019; 18 (1): 167-171

ISSN: $1596-5996$ (print); 1596-9827 (electronic)

(c) Pharmacotherapy Group, Faculty of Pharmacy, University of Benin, Benin City, 300001 Nigeria.

Available online at http://www.tjpr.org

Original Research Article

http://dx.doi.org/10.4314/tjpr.v18i1.25

\title{
Anesthetic and hemodynamic effects of etomidate- remifentanil combination in laparoscopic surgery
}

\author{
Yu Yao', Feng-juan Wang', Jie ${ }^{1}{ }^{1}{ }^{2}$, Zhen-zhong $\mathrm{Wu}^{3}$, Jin-zhuo Wang ${ }^{4}$, \\ Jingming Zhao \\ ${ }^{1}$ Department of Anesthesiology, ${ }^{2}$ Nursing Department, Affiliated Hospital to Changchun University of Chinese Medicine, \\ ${ }^{3}$ Department of Anesthesiology, Jilin Province Qianwei Hospital, ${ }^{4}$ Department of Anesthesiology, Changchun Obstetrics- \\ Gynecology Hospital, ${ }^{5}$ Department of Proctology, Affiliated Hospital to Changchun University of Chinese Medicine, Changchun \\ City, China
}

${ }^{\star}$ For correspondence: Email: rn1164@163.com

Sent for review: 11 October 2018

Revised accepted: 24 December 2018

\begin{abstract}
Purpose: To study the anesthetic and hemodynamic effects of etomidate-remifentanil combination treatment in laparoscopic surgery.

Methods: Patients scheduled for gynecological laparoscopic surgery $(n=120)$ were assigned to test and control groups (60 patients each). Etomidate combined with remifentanil anesthesia was used in the test group, while propofol-remifentanil combination anesthesia was used in the control group. The effect of anesthesia on awakening time, extubation time, pain relief time, systolic blood pressure (SBP), diastolic blood pressure (DBP), and heart rate (HR) of patients before and after the extubation were observed and recorded for the two groups.

Results: Excellent rating was $98.0 \%$ in the test group, and was superior to the corresponding rating of $86.0 \%$ in the control group. Anesthesia time, awakening time, extubation time and pain relief time were markedly shorter in the test group than in controls $(p<0.05)$. However, there were no significant differences in SBP, DBP and HR of patients with tracheal intubation between the two groups $(p>0.05)$. The results were similar in patients with laparoscopic placement. After laparoscopic placement and tracheal extubation, significant decreases in SBP and HR in the test group were seen, relative to control patients $(p<0.05)$.

Conclusion: The anesthetic effect of etomidate combined with remifentanil is superior to that of propofol and remifentanil, and ensures stability of hemodynamic parameters such as SBP, DBP and HR during the period of anesthesia.
\end{abstract}

Keywords: Etomidate, Remifentanil, Propofol, Laparoscopic surgery, Hemodynamic parameters

\begin{abstract}
This is an Open Access article that uses a funding model which does not charge readers or their institutions for access and distributed under the terms of the Creative Commons Attribution License (http://creativecommons.org/licenses/by/4.0) and the Budapest Open Access Initiative (http://www.budapestopenaccessinitiative.org/read), which permit unrestricted use, distribution, and reproduction in any medium, provided the original work is properly credited.

Tropical Journal of Pharmaceutical Research is indexed by Science Citation Index (SciSearch), Scopus, International Pharmaceutical Abstract, Chemical Abstracts, Embase, Index Copernicus, EBSCO, African Index Medicus, JournalSeek, Journal Citation Reports/Science Edition, Directory of Open Access Journals (DOAJ), African Journal Online, Bioline International, Open-J-Gate and Pharmacy Abstracts
\end{abstract}

\section{INTRODUCTION}

Gynecologic laparoscopic surgery is characterized by smaller surgical trauma, higher safety factor, less postoperative complications, and higher efficiency, relative to other surgical procedures. It is a popular surgical procedure in clinics [1,2]. During the operation, signs, hemodynamics, and neuroendocrine system are greatly affected [3]. This is due to the mandatory 
requirement of the 'low head and high foot posture' of the patient, and artificial pneumoperitoneum, which require high surgical anesthesia.

Studies have shown that reasonable and effective anesthesia is the key to successful laparoscopic surgery [4]. Scientific and rational selection of narcotic drugs can effectively reduce the risk of surgery and surgical complications, thus ensuring the safety of patients. Etomidate combined with remifentanil anesthesia has less impact on the respiratory, cardiovascular and nervous system, and is safer and more effective [5]. It is also beneficial to the hemodynamic stability and postoperative recovery of consciousness, and it has no side effects.

The aim of the present study was to investigate the influence of etomidate-remifentanil combination on laparoscopic surgery and its influence on blood pressure, heart rate and other hemodynamic indices.

\section{METHODS}

\section{Patients' profile}

Patients who underwent laparoscopic surgery with general anesthesia $(n=160)$ from January 2015 to January 2016 in our gynecological ward were included as subjects. They were selected and assigned (without bias) to test and control groups (80 cases each) through the random number table method. Subjects having medical history of heart disease, psychosis, coagulopathy and malignancy were excluded. The test group patients had a mean age of $36 \pm 9.2$ years, and their mean weight was $56 \pm 13.2 \mathrm{~kg}$.

The primary diseases comprised 30 cases of uterine fibroids, 34 cases of ovarian cyst, and 26 cases of tubal pregnancy. In the control group, mean age was $39 \pm 11.2$ years, and the mean weight was $61 \pm 9.2 \mathrm{~kg}$. The primary disease consisted of 34 cases of uterine fibroids, 29 cases of ovarian cyst, and 27 cases of tubal pregnancy. Age, gender, weight and primary diseases were comparable between both groups of patients $(p>0.05)$.

The study received approval from the Ethical Committee of Department of Anesthesiology, Hospital Attached to ChangChun University of Chinese Medicine, ChangChun 130000 (approval no. 20184972), and performed according to the guidelines of Helsinki declaration of 1964 as amended in 1996 [6].
Table 1: Basic profile of patients in the two groups

\begin{tabular}{|c|c|c|c|c|c|}
\hline \multirow[b]{2}{*}{$\begin{array}{l}\text { Grou } \\
\text { p }\end{array}$} & \multirow[b]{2}{*}{$\begin{array}{c}\text { Mean } \\
\text { age } \\
\text { (year } \\
\text { s) }\end{array}$} & \multirow[b]{2}{*}{$\begin{array}{c}\text { Weig } \\
\text { ht } \\
(\mathrm{kg})\end{array}$} & \multicolumn{3}{|c|}{ Primary disease } \\
\hline & & & $\begin{array}{c}\text { Uterin } \\
e \\
\text { fibroi } \\
d s\end{array}$ & $\begin{array}{l}\text { Ovari } \\
\text { an } \\
\text { cysts }\end{array}$ & $\begin{array}{c}\text { Tubal } \\
\text { pregnan } \\
c y\end{array}$ \\
\hline Test & $\begin{array}{c}36 \pm \\
9.2\end{array}$ & $\begin{array}{c}53.12 \\
\pm \\
1.25\end{array}$ & 30 & 34 & 26 \\
\hline $\begin{array}{l}\text { Contr } \\
\text { ol }\end{array}$ & $\begin{array}{l}39 \pm \\
11.2\end{array}$ & $\begin{array}{c}54.05 \\
\pm \\
0.81\end{array}$ & 34 & 29 & 27 \\
\hline
\end{tabular}

Data are presented as mean \pm SD $(n=80)$

\section{Anesthesia methods}

All patients for elective surgery were subjected to routine preoperative fasting for $12 \mathrm{~h}$ and were asked to abstain from drinking for at least $6 \mathrm{~h}$. Blood and urine routine, coagulation function and other laboratory tests were carried out. The patients received intramuscular injection of muscle relaxant 30 min before anesthesia. In the operating theatre, peripheral venous access was opened and routinely monitored for vital indicators including pulse, electrocardiogram, and blood pressure, amongst others.

Patients in the test group received $5 \mathrm{mg}$ of midazolam, $0.1 \mu \mathrm{g} / \mathrm{kg}$ remifentanil and $0.2 \mu \mathrm{g} / \mathrm{kg}$ etomidate intravenously. Simultaneously, the control group subjects received intravenous injection of $5 \mathrm{mg}$ of midazolam, remifentanil (1.0 $\mu \mathrm{g} / \mathrm{kg}$ ) and propofol (2 $\mathrm{mg} / \mathrm{kg})$, followed by tracheal intubation. A TCl-111 type venous pump was used to maintain anesthesia during the operation.

Patients in the test group received $4 \mathrm{mg} / \mathrm{kg} / \mathrm{h}$ etomidate and $9 \mathrm{mg} / \mathrm{kg} / \mathrm{h} \quad 0.1 \mathrm{mg}$ (kg.h) 0.1 remifentanil, while $4 \mathrm{mg} / \mathrm{kg} / \mathrm{h}$ propofol, 9 $\mathrm{mg} /(\mathrm{kg} . \mathrm{h})$ remifentanil, and $0.1 \mathrm{mg}(\mathrm{kg} \cdot \mathrm{h})$ triamcinone besylate were administered to the control group. During the procedure, mechanical ventilation was performed to maintain the tidal volume at $8-10 \mathrm{~mL} / \mathrm{kg}$, respiration at $10-15$ times/min, and intra-abdominal pressure at 10 $14 \mathrm{mmHg}$ [6]. Intravenous fluid and infusion rate were adjusted according to the hemodynamic parameters of the patients. Anesthesia was stopped after the surgery, and the tracheal intubation was removed after the patients' consciousness and breathing returned to normal.

\section{Anesthesia index}

The effectiveness of anesthetic effect was classified as either excellent, good or poor [7]. Excellent meant that the patient did not feel pain and there was no restlessness, while good 
meant that the patient had a slight discomfort and occasional restlessness. On the other hand, poor implied that the patient suffered pain and restlessness which seriously affected surgery. The observation indices were centered on changes in hemodynamic parameters such as SBP, DBP, HR, recovery time, extubation time and duration of analgesia before and after surgery. During tracheal intubation, laparoscopic placement and tracheal extubation were noted for the two groups.

\section{Statistical analysis}

Statistical analysis was carried out with SPSS 19.0 statistical software. Data were analyzed using $\chi^{2}$ test. Numeric data are expressed as mean \pm standard deviation (SD) and compared between the two groups using normality test. Paired sample $t$-test was used before and after treatment in the groups, while independent sample $t$-test was used for comparison between groups. Statistical significance was fixed at $p<$ 0.05 .

\section{RESULTS}

\section{Hemodynamic data}

Prior to anesthesia, SBP, DBP, and HR were comparable between both groups of patients. However, after induction of anesthesia, these parameters were significantly reduced in the two groups, relative to their levels before intubation, especially in the control group $(p<0.05)$; SBP, DBP and HR were higher in the test group than in the control group at laparoscopic placement, although the differences were not statistically significant $(p>0.05)$. After laparoscopic placement and tracheal extubation, SBP and HR were significantly lower than the corresponding values in the control group $(p<0.05)$. There was no significant difference in DBP between the two groups $(p>0.05)$.

\section{Anesthetic effects}

Excellent and good rating was $95 \%$ in the test group, which was superior to the corresponding rating of $85 \%$ in the control group $(p<0.05)$.

\section{Extubation time, recovery time, and duration of analgesia after surgery}

Extubation time, recovery time, and duration of analgesia in the test group after surgery were significantly shorter, relative to corresponding control values $(p<0.05)$.

Table 2: Comparison of anesthetic effects between two groups $(\%, \mathrm{n}=80)$

\begin{tabular}{lllll}
\hline Group & Excellent & Good & Poor & $\begin{array}{l}\text { Excellent } \\
\text { plus } \\
\text { good } \\
\text { rating }\end{array}$ \\
\hline Test & $56(70.0)$ & $\begin{array}{l}20 \\
(22.5)\end{array}$ & $4(5.0)$ & $76(95.0)$ \\
Control & $48(60.0)$ & $\begin{array}{l}20 \\
(22.5)\end{array}$ & $(12$ & $68(85.0)$ \\
$P$-value & & & & $<0.05$ \\
\hline
\end{tabular}

Table 3: Changes in SBP, DBP and HR as a function of time in the two groups (mean \pm SD)

\begin{tabular}{|c|c|c|c|c|c|}
\hline Variable & Group & Cases & $\begin{array}{c}\text { SBP } \\
(\mathrm{mmHg})\end{array}$ & $\begin{array}{c}\text { DBP } \\
(\mathrm{mmHg})\end{array}$ & $\begin{array}{c}\text { HR } \\
\text { time (min) }\end{array}$ \\
\hline Before & Test & 80 & $128 \pm 10.25$ & $89 \pm 5.32$ & $80.3 \pm 6.4$ \\
\hline anesthesia & Control & 80 & $130 \pm 9.17$ & $90 \pm 6.22$ & $81.5 \pm 7.4$ \\
\hline Intuhation & Test & 80 & $124 \pm 8.15$ & $85 \pm 4.34$ & $76.3 \pm 4.4$ \\
\hline Intubatıon & Control & 80 & $120 \pm 8.22$ & $81 \pm 4.22$ & $74.2 \pm 5.3$ \\
\hline Laparoscopic & Test & 80 & $136 \pm 9.35^{\mathrm{a}}$ & $92 \pm 6.30^{a}$ & $85.1 \pm 7.1^{a}$ \\
\hline placement & Control & 80 & $132 \pm 10.32$ & $91 \pm 6.28$ & $83.2 \pm 5.8$ \\
\hline After & Test & 80 & $134 \pm 10.12^{b}$ & $89 \pm 7.11^{c}$ & $84.4 \pm 7.1^{\mathrm{b}}$ \\
\hline $\begin{array}{l}\text { laparoscopic } \\
\text { placement }\end{array}$ & Control & 80 & $143 \pm 10.05$ & $95 \pm 6.32$ & $86.3 \pm 6.5$ \\
\hline $\begin{array}{l}\text { After } \\
\text { intubation }\end{array}$ & $\begin{array}{l}\text { Test } \\
\text { Control }\end{array}$ & $\begin{array}{l}80 \\
80\end{array}$ & $\begin{array}{c}137 \pm 8.35^{b} \\
145 \pm 9.22\end{array}$ & $\begin{array}{c}90 \pm 6.38^{c} \\
97 \pm 5.78\end{array}$ & $\begin{array}{c}85.3 \pm 7.3^{b} \\
88.8 \pm 7.1\end{array}$ \\
\hline
\end{tabular}

Values are expressed as mean \pm SD. ${ }^{a} p>0.05$ : SBP, DBP and HR versus control; ${ }^{b} p<0.05$ : SBP and HR versus control; ${ }^{c} p>0.03$ : HR versus control

Table 4: Recovery time, extubation time and duration of analgesia after surgery (mean \pm SD)

\begin{tabular}{lcccc}
\hline Group & No. of cases & Recovery time (min) & Analgesia time (min) & Extubation time (min) \\
\hline Test & 80 & $7.23 \pm 2.58^{\mathrm{a}}$ & $18.03 \pm 2.51^{\mathrm{a}}$ & $12.13 \pm 3.51^{\mathrm{a}}$ \\
Control & 80 & $15.13 \pm 2.12$ & $28.23 \pm 3.11$ & $20.22 \pm 4.01$ \\
\hline${ }^{\mathrm{a}} P<0.05$ & & &
\end{tabular}




\section{DISCUSSION}

The major objective of gynecologic laparoscopic surgery is to achieve surgical treatment with minimal trauma [8]. The operation does not require laparotomy. The avoidance of exposure of the abdominal cavity to the air reduces chances of surgical infection, and leads to reduced trauma and lower incidence of complications, faster wound healing and lower surgical risk, when compared with laparotomy. It is currently the most widely used and minimally invasive surgical procedure in China and abroad [9]. It is essential that the anesthetic drug be effective, sustainable, controllable and highly safe for the short operation time of laparoscopic surgery.

Etomidate is an imidazole derivative with rapid onset and clearance of metabolism in vivo, duration of maintenance and awakening time, and minimal side effects. It is a rapid-acting, safe, and powerful and hypnotic intravenous general anesthetic drug [10]. Studies have found that the hypnotic effect of etomidate is thirteen times as effective as that of thiopental; it mimics aminobutyric acid in reducing cortical inhibition and causing the brain to rapidly enter the sleep mode [11,12]. It has been suggested that etomidate has the effect of inhibiting and activating the brain stem network system [13].

Propofol is an alkyl-based, short-term intravenous, fats-acting anesthesia drug with short duration of action, but it is associated with adverse side effects like respiratory depression, hypotension, thrombosis, and phlebitis [14]. The methyl ester derivative has less effect on the respiratory and circulatory system, and it can reduce the metabolic rate of the brain without affecting cerebral perfusion, thereby significantly reducing vascular injury and intravenous injection pain.

Remifentanil is a novel opioid receptor agonist used for general anesthesia. It takes effect rapidly, with significant analgesic effects, and it can suppress compensatory tachycardia while lowering blood pressure. Remifentanil is hydrolyzed by non-specific esterase in tissues and plasma in vivo; it is not affected by age, sex, and weight, and it is not dependent on liver or renal function. Up to $95 \%$ of remifentanil is excreted in urine, and it can be completely removed from the body within a short time after drug withdrawal, without drug accumulation or respiratory depression [14].

Etomidate-remifentanil combination exerts a rapid anesthetic effect, ensuring stable vital signs and minimal side effects during surgery. Thus, it is most commonly used in laparoscopic surgery. Studies have shown that etomidate combined with remifentanil rapidly puts patients to sleep and ensures hemodynamic stability during surgery $[15,16]$. It has been used as an anesthetic for patients undergoing laparoscopic surgery [17]. A comparison with propofol and remifentanil group revealed that the incidence of postoperative cognitive impairment was significantly lower in the test group than in controls, which shows that the combination has a safe and stable effect on central nervous system function. In another study, it was reported that the recovery time, duration of analgesia, and extubation time in the combined etomidate and remifentanil group were much shortened, relative to those in the propofol-remifentanil combination group when used as anesthesia in cardiac valve replacement, and that the hemodynamic indicators of patients were stable [18].

The combination of etomidate and remifentanil used for gynecological laparoscopic anesthesia in this study was more effective than the propofol and remifentanil combination. The values of SBP, DBP and HR in the two groups following anesthesia induction and tracheal intubation were significantly decreased, relative to their values before anesthesia, especially in the control group. After laparoscopic placement and tracheal extubation, significant decreases in SBP and HR were observed in the test group.

Hemodynamic changes during the operation were minimal, while the anesthetic effect was more stable. The recovery time, extubation time and duration of analgesia after surgery were significantly shorter in the etomidate test group than in controls. This indicates that the rapid anesthetic effect and short anesthesia cycle had a short inhibition time, thereby reducing damage to the central nervous system. Thus, this anesthetic strategy should be promoted clinically.

\section{Limitations of the study}

Few participants were included in this research. Few baseline information was collected and used to adjust the anesthetic and hemodynamic effects of etomidate-remifentanil combination in laparoscopic surgery.

\section{CONCLUSION}

The anesthetic effect of etomidate combined with remifentanil is superior to that of propofol and remifentanil, and ensures stability of hemodynamic parameters such as SBP, DBP and HR during the period of anesthesia. 


\section{DECLARATIONS}

\section{Conflict of Interest}

No conflict of interest associated with this work.

\section{Contribution of Authors}

We declare that this work was done by the author(s) named in this article and all liabilities pertaining to claims relating to the content of this article will be borne by the authors. All authors read and approved the manuscript for publication. Feng-juan Wang conceived and designed the study. Yu Yao, Feng-juan Wang, Jie Liu, Zhen-zhong $\mathrm{Wu}$, Jin-zhuo Wang collected and analyzed the data, while Yu Yao wrote the manuscript.

\section{REFERENCES}

1. Xia L. Remifentanil combined with propofol in the application of anesthesia for thyroidectomy 35 cases. Chin J Ethnomed Ethnopharm 2016; 23: 112-114.

2. Liu HO. Remifentanil-targeted infusion of compound etomidate for anesthesia induction in heart valve replacement. Chin J Mod Drug Appl 2016; 10(16): 127128.

3. Hiroaki K, Naohiro O, Kimiko K, Takako K, Michiko K, Yayoi M, Yasuo MT, Shinji K, Katsuya T, Shuzo $O$. Effects of a novel method of anesthesia combining Propofol and volatile anesthesia on the incidence of postoperative nausea and vomiting in patients undergoing laparoscopic gynecological surgery. Bras $J$ Anesthesia 2016; 66(1): 12-18.

4. Pascal M, Lionel B, Benoît V, Mohamed H, Bernard A, Emmanuel B. Hypobaric Unilateral Spinal Anaesthesia versus General Anaesthesia in Elderly Patients Undergoing Hip Fracture Surgical Repair: A Prospective Randomised Open Trial. Turk J Anaesthesiol Reanim 2018; 46(2): 121-130.

5. Yong HG, Xiao XD. Comparative observation of the effect of etomidate and propofol on circulatory system and the depth of anesthesia in laparoscopic surgery of ectopic pregnancy. Chin J Biochem Pharm 2016; 36(9): 55-88.

6. World Health Organization. Declaration of Helsinki. Br Med J 1996; 313(7070): 1448-1449.

7. Wang YQ, Yang $X$. Anesthetic effect of remifentanil combined with propofol for laparoscopic cholecystectomy. Public Med Forum Mag 2017; 22(1): 2940-2941.

8. Kang LN. Clinical effect of remifentanil combined with propofol in gynecological laparoscopic anesthesia. Chin $J$ Clin Ration Drug Use 2017; 11(5): 56-57.

9. Ma BJ, Ren WW. Effects of different doses of remifentanil on pain perception in patients undergoing gynecologic laparoscopic surgery. Chin Prac Med 2016; 6(9): 182183.

10. Yang $L$, Wen $C$, Yu $L$, Yun $W$, Ren $L$, Yun $Y$, An SW. Changes in duration of action of rocuronium following decrease in hepatic blood flow during pneumoperitoneum for laparoscopic gynaecological surgery. BMC Anesthesiol 2017; 17(1): 45.

11. Yuka U, Fumika S, Nobuhiro T, Koji H, Eri M, Taro I, Hitomi F, Takehiko I, Yuji M. Comparison of the analgesic efficacy of ultrasound-guided rectus sheath block and local anesthetic infiltration for laparoscopic percutaneous extraperitoneal closure in children. Paediatr Anaesth 2017; 27(5): 516-523.

12. Shimizu R, Kawahara R, Hanada R, Okuno S, Yamasaki, Tamai $Y$, Kawahara H. A combination of ultrasoundguided rectus sheath and transversus abdominis plane blocks is superior to either block alone for pain control after gynecological transumbilical single incision laparoscopic surgery. Clin Exp Obstet Gynecol 2016; 43:504-508.

13. Santiago M, Alba P, Miriam G, Ana ML, Olga O, Blanca $T$, Jesús L. An Exploratory Study of Sevoflurane as an Alternative for Difficult Sedation in Critically III Children. Pediatr Crit Care Med 2018; 30: 156-158.

14. Aleida GH, Kim B, Loes B, Benedictus CS, Huib AAMV. Laparoscopic Sterilization Under Local Anesthesia with Conscious Sedation Versus General Anesthesia: Systematic Review of the Literature. J Minim Invasive Gynecol 2018; 25(3): 393-401.

15. Shinju $O$. Dexmedetomidine as an adjuvant during general anesthesia. J Anesth 2018; 32(3): 313-315.

16. Sanli M, Begec Z, Kayhan GE, Ozgul U, Ucar M, Yologlu $S$, Durmus M. Comparison of the proseal, supreme, and i-gel SAD in gynecological laparoscopic surgeries. Scientific World J 2015; 2015(11): 634320.

17. Jia DJ. Effects of etomidate and remifentanil in total intravenous anesthesia in patients undergoing abdominal surgery. Mod Prev Med 2013; 5(12):996-999.

18. Seol T K, Lim J K, Yoo E K, Min SW, Kim CS, Hwang JY. Propofol-ketamine or propofol-remifentanil for deep sedation and analgesia in pediatric patients undergoing burn dressing changes: a randomized clinical trial. Pediatr Anesth 2015; 25(6): 560-566. 